NBER WORKING PAPER SERIES

\title{
THE QUALITY OF LABOR RELATIONS AND UNEMPLOYMENT
}

\author{
Olivier Blanchard \\ Thomas Philippon \\ Working Paper 10590 \\ http://www.nber.org/papers/w10590
NATIONAL BUREAU OF ECONOMIC RESEARCH 1050 Massachusetts Avenue
Cambridge, MA 02138
June 2004

We thank Emmanuel Farhi for excellent research assistance. We thank Giuseppe Nicoletti, Gian Maria Milesi-Ferretti, Jim Snyder for help with data. We thank Daron Acemoglu, Roland Benabou, Xavier Gabaix, Ricardo Caballero, Pierre Fortin, Richard Freeman, Peter Hall, Francis Kramarz, and Andrei Shleifer for discussions. The views expressed herein are those of the author(s) and not necessarily those of the National Bureau of Economic Research.

(C)2004 by Olivier Blanchard and Thomas Philippon. All rights reserved. Short sections of text, not to exceed two paragraphs, may be quoted without explicit permission provided that full credit, including (C) notice, is given to the source. 
The Quality of Labor Relations and Unemployment

Olivier Blanchard and Thomas Philippon

NBER Working Paper No. 10590

June 2004

JEL No. E24, J5, J64

\section{ABSTRACT}

In countries where wages are primarily set by collective bargaining, the effects on unemployment of changes in the economic environment depend crucially on the speed of learning of unions. This speed of learning is likely to depend in turn on the quality of the dialogue that unions have with firms, on what can more generally be called the quality of labor relations. In this paper, we examine the role this quality of labor relations has played in the evolution of unemployment across European countries over the last 30 years. We conclude that it has played an important role: Countries with worse labor relations have experienced higher unemployment. This conclusion remains even after controlling for labor institutions.

Olivier Blanchard

Department of Economics

MIT

Cambridge, MA 02142

and NBER

blanchar@mit.edu

Thomas Philippon

NYU

Stern School of Business

Department of Finance

44 West $4^{\text {th }}$ Street, Suite 9.03

New York, NY 10012-1126

tphilipp@stern.nyu.edu 


\section{Introduction}

In countries where wages are primarily set by collective bargaining, the effects on unemployment of changes in the economic environment are likely to depend crucially on the speed of learning of unions.

This speed of learning is likely to depend in turn on the quality of the dialogue that unions have with firms, on what can more generally be called the quality of labor relations.

In this paper, we examine the role this quality of labor relations has played in the evolution of unemployment across European countries over the last 30 years. We conclude that it has played an important role.

We start, in Section 1, with a "case study", that of the Netherlands. After increasing to $11 \%$ in the early 1980 s, Dutch unemployment turned around, reaching a low of $2 \%$ in the early 2000 s. This turnaround is directly traceable to wage moderation. This wage moderation appears directly traceable in turn to the dialogue between unions and firms, and to the unions' commitment to reestablish sufficient profit margins so as to increase capital accumulation and employment.

We then present, in Section 2, a simple model of wage determination and unemployment. We show how the effects on unemployment of different changes in the economic environment depend crucially on the perceptions of unions and their speed of learning.

We then turn, in Section 3, to the cross country evidence. We construct two measures of the quality of labor relations, the first based on strike intensity in the 1960s, the other based on surveys of managers in the 1990s. We show that countries with worse labor relations have experienced higher and longer-lasting unemployment. We show that the effect remains even after controlling for labor market institutions. 


\section{The Netherlands}

The evolution of unemployment in the Netherlands since the early 1980s is often called the "Dutch unemployment miracle" ${ }^{1}$ After increasing from $2 \%$ in 1970 to $11 \%$ in 1983, the unemployment rate turned around, decreasing steadily to reach a low of $2 \%$ in 2001 . Today, it has increased back to $6 \%$, but most of the increase since 2001 appears to be cyclical.

The focus on the unemployment rate is not misleading. It is sometimes argued that the increase in employment has come from job sharing, from an increase in part-time employment. This is not correct: The increase in part-time employment, which has indeed been substantial, has been more than matched by an increase in the participation rate, in particular by an increase in the participation rate of women. It is also argued that the decrease in unemployment hides a high number of workers on disability. While it is true that disability rolls are still very high, they have decreased with unemployment, and thus cannot account for the decrease in unemployment.

There is general agreement that the proximate source of the turnaround in unemployment is wage moderation. This can be seen in Figure 1, which plots the unemployment rate and the $(\log )$ wage in efficiency units. The wage (or more precisely the labor cost, as the measure includes both the wage and non-wage benefits) in efficiency units is constructed under the assumption of Harrod neutral technological progress, following Blanchard [1997]; it is normalized to equal zero in 1970-71. On a balanced growth path with constant unemployment, the wage in efficiency units should be constant. Thus, one can think of decreases in this wage measure as reflecting wage moderation. As Figure 1 indicates, the wage in efficiency units has indeed decreased steadily since the early 1980s, standing in 2001 at $83 \%$ of its 1970 value; this decrease is substantially larger than the decrease of the

1. Two useful references are Visser and Hemerijck [1997], and Nickell and Van Ours [2000]. 
same variable for the European Union as a whole. This wage moderation has led to an increase in profit, which has led to an increase in capital accumulation, and an increase in employment over time.

\section{Figure 1. Unemployment and wage in efficiency units, in the} Netherlands, 1970-2002.

There is also general agreement that the start of this wage moderation can be traced to a particular event, the "Wassenaar Accord," signed at the end of 1982 between unions, business organizations and the government. At that time, unemployment had increased very quickly, and profit and investment rates had collapsed. Unions, explicitly recognizing the need to reestablish profit margins, agreed to wage moderation. Despite tensions along the way, this commitment to wage moderation has remained to this day.

This short description may give the impression of a process smoother than it actually was. The Wassenaar Accord was preceded by nine attempts and nine failures in the previous nine years. The Accord itself was a complex agreement, with much give and take, including a commitment by firms to consider decreasing working time (at the same wage per hour). Yet, it remains the case that the turnaround in wage setting happened earlier in the Netherlands than in other European countries, and observers credit it and its subsequent follow-through to a long-standing tradition of dialogue between unions and firms. Katzenstein [1985] for example attributes it to "corporatism," which he defines as "an ideology of partnership, expressed at the national level ( ); and voluntary and informal coordination of conflicting objectives through continuing bargaining between interest groups, state bureaucracy, and political parties."

An important question, in light of the research on the causes of unemployment, is how much of the decrease in Dutch unemployment can be 


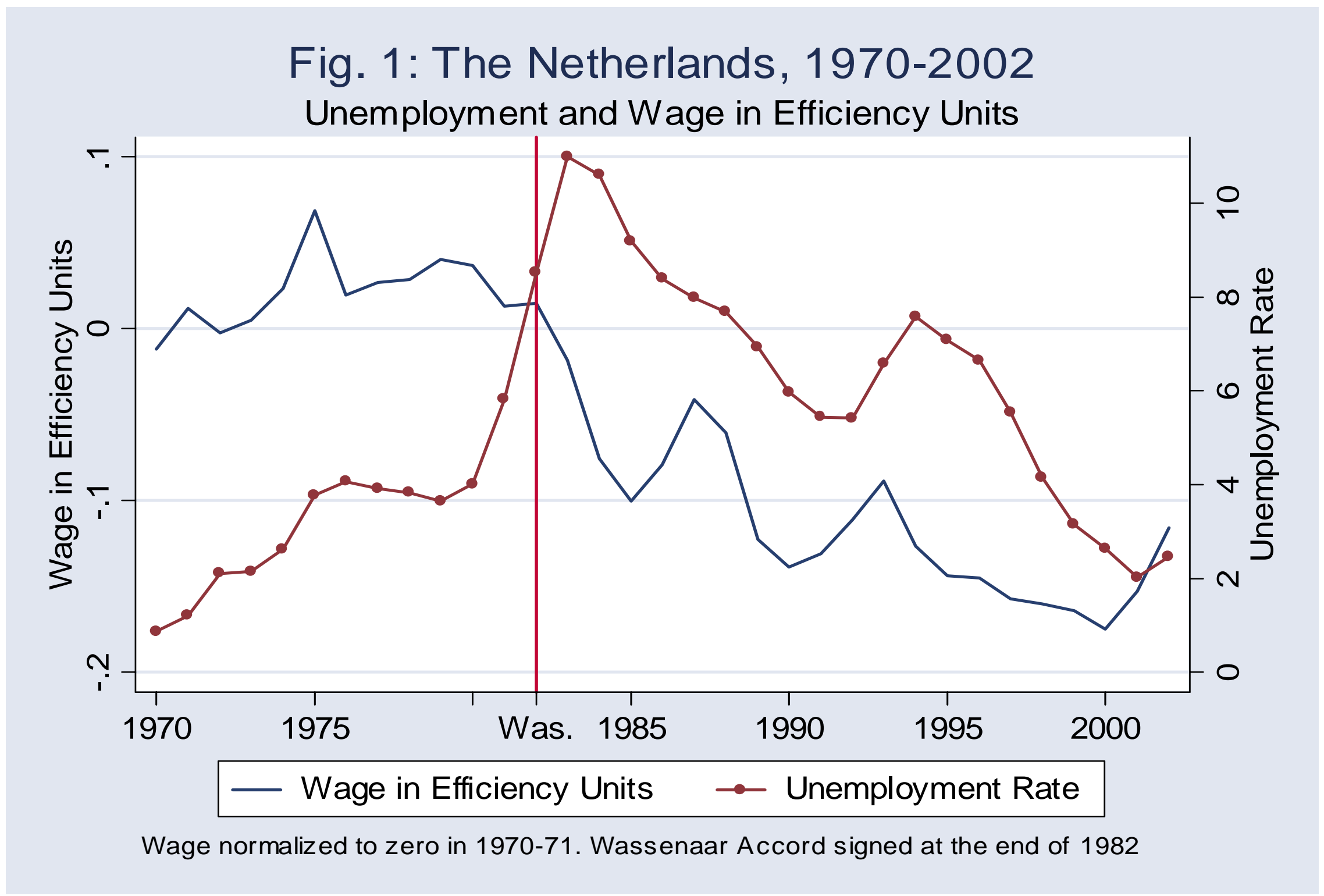


attributed directly to this change in union attitudes given labor market institutions, and how much can be attributed to reforms of these labor market institutions. The question goes beyond the scope of this paper (see Nickell and Van Ours [2000] for an exploration, Schettkat [2003] for a careful characterization of institutions and institutional change), but one can make the following remarks:

The period since 1982 has seen a number of reforms of the Dutch labor market. These reforms have however taken place in the late 1980s and the 1990s, thus some time after the start of wage moderation and the start of the decline in unemployment. The reforms have typically not been radical; rather, they have reduced some of the distortions associated with a given level of social insurance, rather than decreased that level. A decrease in replacement rates, and the conditioning of benefits on the acceptance of "suitable jobs" have decreased the incentives to remain unemployed. Experience rating of firms according to their history of worker disabilities have decreased the incentives for firms and workers to use disability programs as alternatives to unemployment. In general, however, the Dutch system of social insurance remains more generous than the EU average, indeed more generous than the average of the four largest EU countries-France, Germany, Spain, and Italy - that today have much higher unemployment than the Netherlands.

\section{Shocks, learning, and unemployment}

The purpose of this section is to show that the effects of shocks on unemployment depend very much on whether and how fast they are perceived by unions. The model we present makes no claim to generality; its goal is to introduce some of the major shocks which are typically thought to have been behind movements in unemployment in Europe over the last 30 
years, and show how, in each case, the response of unemployment depends crucially on union's perceptions.

- Assume an aggregate production function of the form:

$$
y=\min (k, a n)
$$

where $y, k, n$ are output, capital, and employment respectively, and $a$ captures Harrod neutral technological change. The profit rate is then given by:

$$
\pi=\frac{y-w n}{k}=1-\frac{w}{a}
$$

- Assume that the supply of capital is given by:

$$
k=a(1+\theta(\pi-r))
$$

where $r$ is the user cost faced by firms, and the parameter $\theta$ measures the response of the supply of capital to net profit - the profit rate net of the user cost. The presence of $a$ on the right hand side is to insure the existence of a balanced growth path, where capital and output increase at the same rate.

The first two assumptions together imply a labor demand schedule given by:

$$
n=\frac{k}{a}=1+\theta(\pi-r)=1+\theta\left(1-\frac{w}{a}-r\right)
$$

- Assume an economy wide union, acting as a monopoly union, and maximizing the wage bill, $w n$, subject to the perceived labor demand schedule:

$$
n=1+\hat{\theta}\left(1-\frac{w}{\hat{a}}-\hat{r}\right)
$$


Note that we allow union perceptions of $\theta, a$, and $r$, all denoted by hats, to differ from the actual values of these three parameters.

The assumption that the union chooses the wage unilaterally, subject to the perceived labor demand, is not particularly realistic. It is however convenient, and allows us to avoid an interesting but difficult issue, the nature of bargaining when the two sides (the firms and the union) differ in their perceptions. Here, only the union's perceptions matter for the choice of the wage.

- The wage implied by this maximization is given by:

$$
w=\frac{\hat{a}}{2}\left(1-\hat{r}+\frac{1}{\hat{\theta}}\right)
$$

and employment is given by equation (1) (firms are assumed to know the true parameters).

If perceptions are correct, employment is given by:

$$
n=\frac{1+\theta(1-r)}{2}
$$

Keeping $\theta$ and $r$ constant, the economy follows a balanced growth path, where capital, output, and real wages grow with $a$, and where employment remains constant.

Now consider three types of shocks.

- $\quad$ Suppose there is a slowdown in productivity growth, a decrease in the rate of growth of $a$, as was indeed the case in Europe starting in the mid-1970s.

If perceptions are correct, so $\hat{a}$ remains equal to $a$, wages adjust in line with $a$, and, as equation (3) indicates, employment remains constant. If however perceptions do not fully adjust, so $\hat{a}$ exceeds $a$ for some time, employment will be lower until $\hat{a}$ converges back to $a$. 
- $\quad$ Suppose there is a sharp increase in the real interest rate, as was indeed the case in the 1980s and early 1990s in most European countries. Even if perceptions are correct, so $\hat{r}$ remains equal to $r$, employment will decrease as unions prefer to cut both the wage and employment. If perceptions do not adjust however, the wage does not change, and the decrease in employment will be larger.

- $\quad$ Suppose, last, that there is an increase in capital mobility, an increase in $\theta$. This evolution has been less studied than the previous two, but has clearly taken place in Europe over the last 30 years, and may be quite relevant: The elimination of capital controls and the reduction of other barriers to capital movements have surely increased the elasticity of capital to its rate of return. So has the widespread process of privatization: Private owners are typically much more sensitive to the rate of return than the state.

Under the assumption that perceptions are correct, such an increase in $\theta$ leads to an increase in employment: The higher elasticity of capital to the profit rate, and by implication the higher elasticity of employment to the wage, lead the union to moderate its wage demands, and thus lead to an increase in employment. If perceptions do not change however, wages do not adjust, and employment may actually decrease. This depends on whether, initially, firms were making positive or negative net profits. If net profits, $1-w / a-r$ were initially negative, employment will initially decrease, as capital moves out. Only over time, as perceptions and wages adjust, will employment recover and end up ultimately higher.

In all these cases, the specific dynamics of adjustment will depend on the speed at which unions learn and adjust wages. The speed of learning is likely to depend in turn on how easy these changes in the economic environment are to identify. Productivity growth, measured, say, by TFP growth, has a large transitory component from year to year. It clearly took a while for 
the slowdown of the mid 1970s to be fully perceived (not only by unions, but by economists and policy makers as well); for some time, the slowdown was largely hidden from view by the effects of the two oil price increases. Changes in interest rates should be easier to observe, although unions may not fully perceive the implications for investment and ultimately for employment. Increases in capital mobility may also be hard to assess. Indeed, some unions in Europe still speak as if profits were largely rents to be appropriated by workers, without implications for employment. While such rhetoric may have been appropriate in some parts of the economy in the past, it is surely not a good assumption about capital mobility today.

Formally introducing uncertainty and learning raises a number of conceptual issues. First, firms, under the maintained assumption that they perceive the changes accurately, may want to be strategic, for example cutting employment more than implied by the static labor demand in order to convince unions that the world has changed. Second, unions may want to experiment, to move the wage in order to learn faster about the relevant parameters. We leave both of these issues aside, and focus on what strikes us as the main effect of uncertainty and learning, namely that it takes some time for unions to learn, and thus to adjust the wage.

So assume that labor demand is still given by equation (1) (so firms are not strategic), and that unions maximize the expected wage bill period by period (so they have no incentive to experiment ${ }^{2}$ ).

Consider the case where only productivity $a$ is stochastic, and assume that it follows:

$$
\log \left(a_{t}\right)=\log \left(a_{t}^{*}\right)+\epsilon_{t}, \quad \log \left(a_{t}^{*}\right)=\log \left(a_{t-1}^{*}\right)+\tilde{g}
$$

2. In fact, for the case we consider below, namely uncertainty about productivity $a$, unions have no incentive to experiment since the signal to noise ratio does not depend on the wage they set. This is no longer the case when unions are uncertain about the elasticity of capital supply, $\theta$. 
where $\epsilon_{t}$ is i.i.d. normal, and $\tilde{g}$ can take one of two values, $\tilde{g}=g$ or $\tilde{g}=0$. In words, actual productivity is equal to underlying productivity plus white noise. Underlying productivity growth is either positive or zero.

To capture what happened in the mid 1970s, suppose that underlying productivity growth decreases from $g$ to 0 . Unions will learn and adjust wages at a rate which will depend on the tightness of their prior and the standard deviation of the transitory component. Figure 2 shows such a path, both for the wage in efficiency units $w_{t} / a_{t}$ and for employment (which is the mirror image of the wage), based on an initial subjective probability that $\tilde{g}=g$ equal to 0.98 , a standard deviation of the transitory shock of $2 \%$, and a value of $g$ of $1 \%$ (the derivation of the path is given in the appendix.)

\section{Figure 2. The response of wages in efficiency units to a decrease} in productivity growth.

The main feature of Figure 2 is the hump shaped response of the wage in efficiency units, which, given the static labor demand function, implies a hump shaped response of employment and of unemployment. As productivity growth slows down, wage growth also decreases but still exceeds productivity growth for some time. This leads to an increase in the wage in efficiency units for some time, until it turns around and returns to its steady state value. For the parameters we have chosen, this leads to an increase in wages in efficiency units of about $5 \%$ at the peak, an increase roughly consistent what is observed in the data at the end of the 1970s for the European Union as a whole.

Similar dynamics can be derived with respect to the other shocks, be it an increase in interest rates, or an increase in capital mobility. An increase in capital mobility, even if it ultimately leads to an increase in employment, may well also generate a hump shape response of unemployment, with an initial increase, followed by a larger decrease later on. 


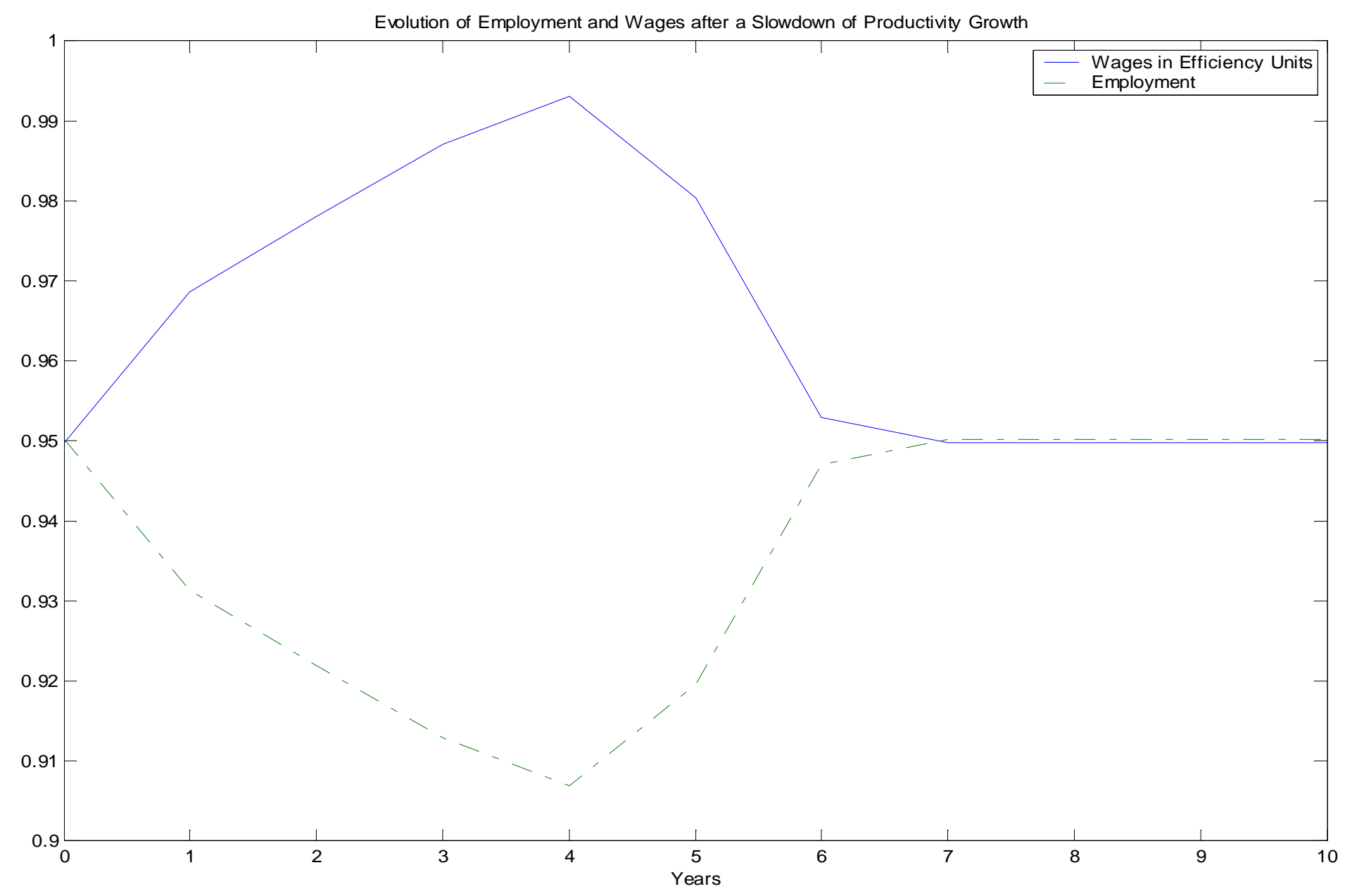

Figure 2: Simulations of Wages and Employment after Slowdown in TFP growth. 


\section{Learning, the quality of labor relations, and unemployment}

What might lead to different speeds of learning and adjustment by unions? Bayesian learning points to differences in the tightness of priors, and the informativeness of signals. More generally, it points to differences in ideology, and differences in the quality of labor relations: The more unions and firms share a common economic model, or the more they discuss the economic implications of different shocks, the faster learning and adjustment is likely to be.

\subsection{Quality of labor relations and unemployment}

With this motivation in mind, we construct and study the effects of two measures of the quality of labor relations across OECD countries.

- $\quad$ The first is a measure of strike intensity, from 1960 to 1967. The motivation for looking at strike activity is a simple one: most of the theoretical and empirical work on strikes suggests that the quality of labor relations is an important determinant of strike activity (see, for example, Hibbs [1987].) The motivation for choosing the period 1960 to 1967 is that this predates the increase in unemployment that we want to explain. The reason for stopping in 1967 rather than, say, 1970, is that, in the late 1960s, many European countries, especially France, Germany, and Italy, were affected by social and political unrest, for reasons largely unrelated to the quality of labor relations.

Two measures of strike activity are available for the 1960s for most OECD countries. The first is a measure of days lost in strikes (DL), the second a measure of workers involved in strikes (WI). We express both as ratios to employment. When needed, we combine them in one measure, STRIKE, which we define by the maximum of normalized 
days lost and normalized workers involved:

$$
\operatorname{STRIKE}_{i}=\max \left\{\frac{D L_{i}}{\operatorname{std}(D L)}, \frac{W I_{i}}{\operatorname{std}(W I)}\right\}
$$

The standard deviations are the cross country standard deviations. The motivation for using the max specification is that not all strikes are recorded, while all recorded strikes actually happened, so both measures are likely to be lower bounds on strike activity.

As an explanatory variable, this measure presents two problems. The first is that, in the 1960s, two OECD countries, Spain and Portugal, were dictatorships, where strike activity was illegal. We have no other choice, when using this measure, than to drop these two countries from the sample. The second is that strike activity depends on other variables than the quality of labor relations, some of them observable (such as unemployment during the period), some of them unobservable. This implies that using strike activity as a proxy for quality in a regression entails measurement error. We shall return to the issue below.

- $\quad$ The second measure is a direct, survey, measure. In 1999, the World Economic Forum asked the following question to managers of firms in a large number of countries: "Are labor relations in your firm cooperative?". The answer was given on a scale from 0 to 7 . We use the country mean response as our second measure of the quality of labor relations, and denote it by "COOP".

Clearly, this second variable is closer to what we want to capture than the first. It suffers however from an obvious problem of potential reverse causality, as perceptions of the quality of labor relations by firms in 1999 may well reflect in part the evolution of unemployment since the 1960s. (A similar question was asked in 1993. This is however also quite late in the period, and the 1993 and 1999 measures are very highly correlated). 
If we think of the quality of labor relations as a stable feature of an economy, a natural question is how correlated the two measures of quality are. The answer is given in Figure 3, which plots COOP against STRIKE, for the 18 OECD countries for which both measures exist. As can be seen, there is a strong negative relation between the two (The $R^{2}$ of the regression of COOP on STRIKE is equal to 0.62, the t-statistic on the coefficient on STRIKE is equal to -5.0). This is good news for our implicit maintained hypothesis that the quality of labor relations is a relatively stable characteristic of countries over time.

\section{Figure 3. Cooperation in 1999 versus Strikes in 1960-1967}

We can then turn to the relation between unemployment and the quality of labor relations over time. To do so, we divide the period 1965-2002 into decades (more specifically 1965-1974, 1975-1984, 1985-1994, and 19952002), and for each decade, we regress:

$$
u_{i t}=a_{t}+b_{t}\left(\text { quality measure }{ }_{i}\right)+e_{i t},
$$

where $u_{i t}$ is the mean unemployment rate in decade $t$ in country $i$. For each $t$, the coefficient $a_{t}$ captures the common evolution of unemployment across countries during the decade. Our interest is in the coefficient $b_{t}$, which captures the extent to which differences in the quality measure can explain differences in unemployment across countries during the decade.

Table 1. The quality of labor relations and unemployment rates, by decade

Basic results are reported in Table 1. The first regression reports the results of estimation using the COOP measure. The second regression reports the results of estimation using the STRIKE measure (Both are normalized by 


\section{Fig. 3: Labor Relations and Labor Conflicts}

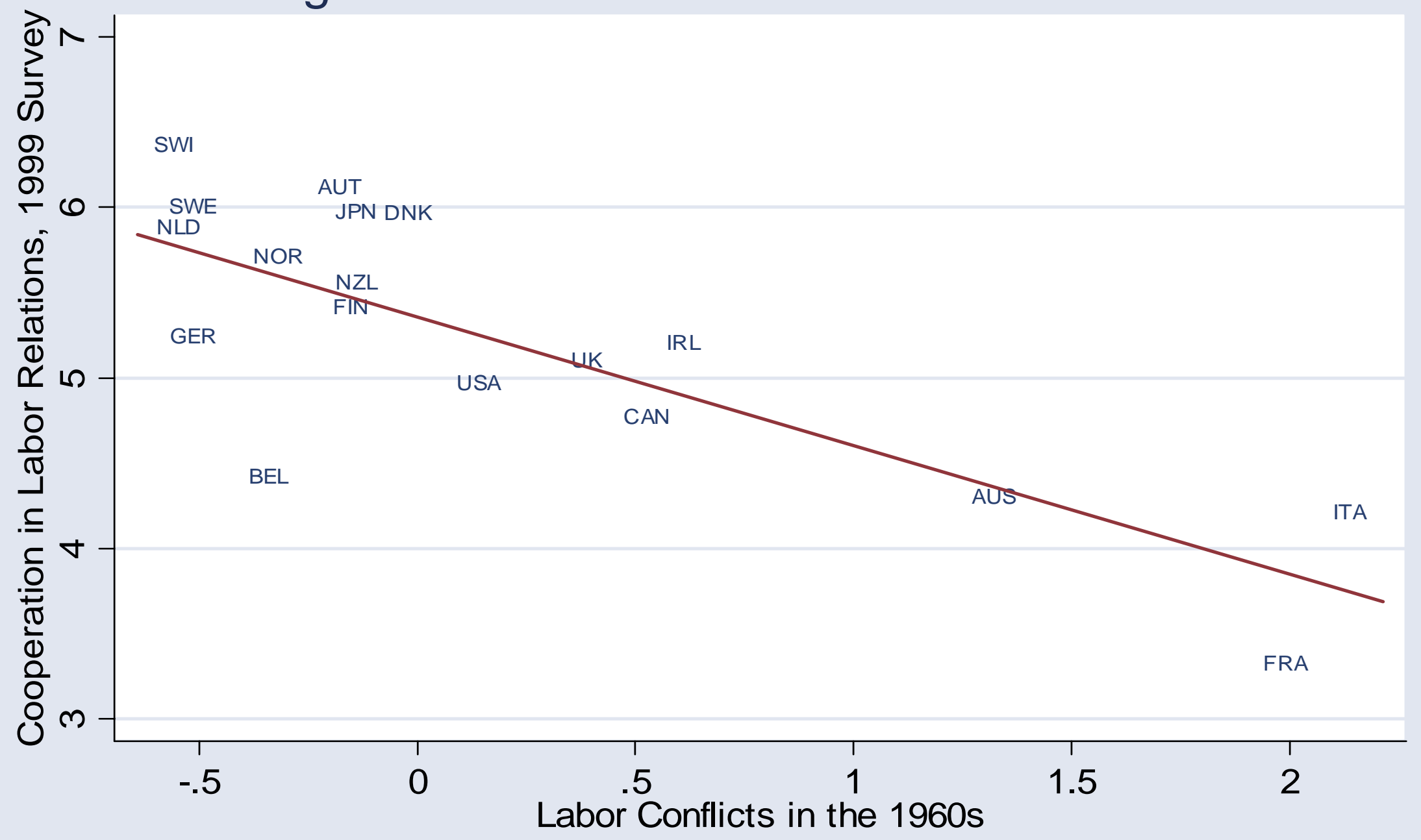

See main text for description of measure of labor conflicts 
Table 1: Labor relations and unemployment in 4 decades. Dependent variable is average unemployment over the decade. Three regressions are run for each decade, with a different RHS variable. Figure 4 corresponds to the first regression (Cooperation, OLS). Standard errors are in italics.

\begin{tabular}{|c|c|c|c|c|c|}
\hline & Time period & $1965-74$ & $1975-84$ & $1985-94$ & 1995-2002 \\
\hline \multirow{4}{*}{  } & \multirow{2}{*}{$\begin{array}{l}\text { Cooperation in labor } \\
\text { relations (OLS) }\end{array}$} & -0.904 & -1.769 & -2.582 & -2.548 \\
\hline & & 0.406 & 0.648 & 0.761 & 0.571 \\
\hline & $\mathrm{N}$ & 20 & 21 & 21 & 21 \\
\hline & $\mathrm{R} 2$ & 0.216 & 0.282 & 0.377 & 0.512 \\
\hline \multirow{4}{*}{ 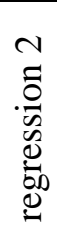 } & \multirow{2}{*}{$\begin{array}{lll}\text { Strike activity in } \\
1960 \text { 's }\end{array}$} & 0.967 & 1.515 & 2.219 & 1.785 \\
\hline & & 0.432 & 0.712 & 0.766 & 0.572 \\
\hline & $\mathrm{N}$ & 17 & 18 & 18 & 18 \\
\hline & $\mathrm{R} 2$ & 0.251 & 0.221 & 0.344 & 0.379 \\
\hline \multirow{4}{*}{ 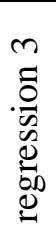 } & \multirow{2}{*}{$\begin{array}{l}\text { Cooperation in labor } \\
\text { relations (IV) }\end{array}$} & -0.9 & -1.444 & -2.484 & -2.461 \\
\hline & & 0.633 & 0.928 & 1.017 & 0.695 \\
\hline & $\mathrm{N}$ & 17 & 18 & 18 & 18 \\
\hline & $\mathrm{R} 2$ & 0.19 & 0.325 & 0.412 & 0.532 \\
\hline
\end{tabular}

Note: Cooperation in labor relation is, from 1999 survey of managers, the answer to question: "Are labor relations in your firm cooperative?". Strike activity per employee from 1960 to 1967 is a composite measure based on employees involved and days lost. Last regression (IV) uses days lost and employees involved in strikes in the 1960's to instrument for 1999 survey measure. 
their standard deviation, so the coefficients are directly comparable.) For reasons discussed earlier, both of these regressions suffer from potential bias, measurement error for the first, simultaneity bias for the second. Thus, in the third line, we report the results of estimation, using days lost per employee and workers involved as instruments for COOP. If, as plausible, the measurement error in using the strike measure is uncorrelated with the disturbance term in the above regression, this yields consistent estimates of the effect of the quality of labor relations on unemployment for each decade.

All three regressions suggest a strong and significant effect of the quality of labor relations on unemployment. The magnitudes are largely similar across the two measures, and across OLS and IV estimation. Countries with one-standard deviation better quality had about $1 \%$ less unemployment than the average OECD country in 1965-1974, about 1.5 to $2 \%$ less unemployment in 1975-1984, about 2 to $2.5 \%$ in 1985-1994, and 1995-2002. To give a better sense of the results, Figure 4 plots the unemployment rate against COOP, and the OLS regression line for each of the four decades. The relation is quite striking, especially in the last two periods.

Figure 4. The quality of labor relations and unemployment rates, by decade

Standard checks suggests that this relation is robust. Figure 4 makes clear that the results are not driven by any single country. Using the underlying components DL and WI separately rather than combined in CONF makes little difference to the results. So does the use of the 1993 answers instead of the 1999 answers to the World Economic Forum survey. So does controlling for the average unemployment rate in 1960-1967. Estimating equation (4) using annual unemployment rather than decadal averages) yields a time series for estimated $\hat{b_{t}}$ which is hump shaped, reaching a peak in the mid 1980 s, and decreasing at the very end of the sample. 


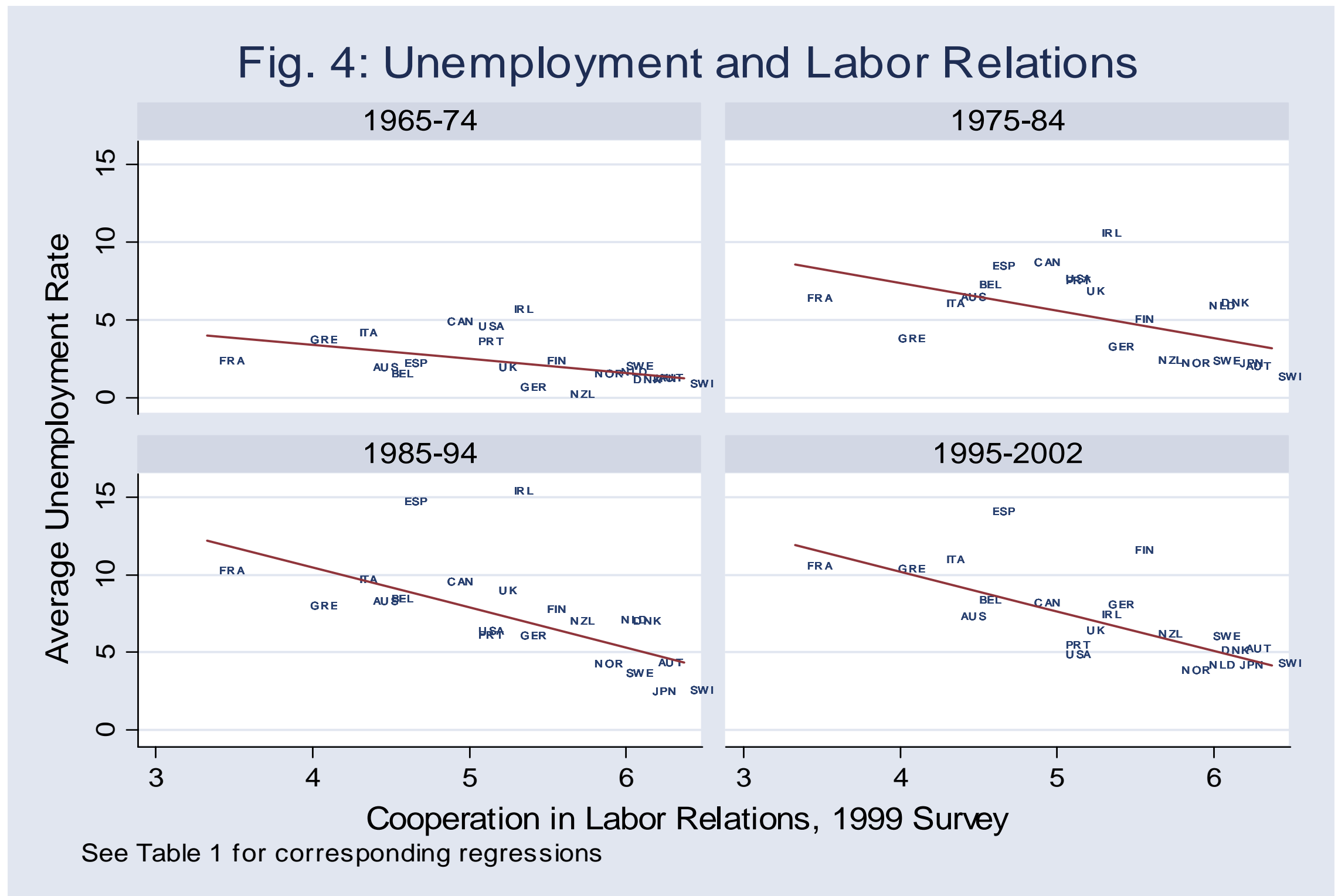




\subsection{The quality of labor relations, Institutions, and unemployment}

An obvious question at this point is whether the quality of labor relations affects unemployment directly, i.e. given labor market institutions, or through these institutions themselves. The earlier description of the Netherlands suggests the presence of at least some direct effect: Institutions were reformed only after wage moderation started. We now look at the cross country evidence.

A natural starting point is to use a specification which allows for an effect of institutions on unemployment, and then add our measure of quality. Such a specification was suggested and explored in earlier work by one of the two authors [Blanchard and Wolfers 2000]. We use that specification as a benchmark and estimate:

$$
u_{i t}=\left(1+d_{65-74}+d_{75-84}+d_{85-94}+d_{95-03}\right)\left(\alpha+\sum_{j} \beta_{j} X_{i j}\right)+\varepsilon_{i t}
$$

We divide time in 4 decades: 1965-74, 1975-84, 1985-94, 1995-2003 (We use decades to make the results more comparable to the results presented earlier. Using half decades as in Blanchard and Wolfers makes little difference to the results.) $u_{i t}$ is unemployment in country $i$ and decade $t$, and $X_{i j}$ is a measure of institution $j$ in country $i$. This specification allows for the impact of the common (unobservable) aggregate shock $d_{t}$ to depend on a linear combination of the different measures of institutions. The institutions (described in Blanchard and Wolfers) are the replacement rate, an index of the length of time for which unemployment benefits are paid, union coverage, an index of employment protection, an index of active labor market policies, union density, a measure of the tax wedge between the cost of labor to firms and take-home pay by workers, and a measure of 
coordination of bargaining.

\section{Table 2: Shocks and institutions revisited}

Results of estimation of this non-linear specification are given in Table 2.

The first column uses only COOP, instrumented by STRIKE. This specification can be thought as the same as equation (4), with the additional constraint across time periods that $b_{t} / a_{t}=$ constant. This additional constraint is close to being satisfied by the unconstrained regressions, so the results are very similar, and our measure of labor quality is, as in Table 1, very significant.

The second column uses only the variables in Blanchard and Wolfers, and the results are, in general, similar to theirs. Institutions are defined so that their expected sign on unemployment is positive; all coefficients turn out to have the expected sign, although only the last 4 are significant.

The third column uses both institutions and our measure of quality. The coefficient on the measure of quality decreases from -0.927 to -0.638 , but remains very significant. Interestingly, the coefficients on most institutions become more significant than in column 2 . One might have expected the "coordination" variable and our quality variable to capture similar dimensions of labor relations and be very collinear; this is not the case (the correlation between the two is 0.42 ), and both dimensions are strongly significant.

Column 4 excludes labor market institutions that were not significant in column 3. The estimated coefficient for the quality of labor relations goes up to -0.834 , and is just as significant as in column 1 . 
Table 2: Unemployment over time and across countries. Dependent variable is average unemployment in country i (18 countries) in decade t (4 decades, 1965-1975-1995-2003). Model is estimated using NLLS (non-linear least squares). Standard errors are in italics .

\begin{tabular}{|c|c|c|c|c|}
\hline & 1 & 2 & 3 & 4 \\
\hline \multicolumn{5}{|l|}{ Variable } \\
\hline \multirow[t]{2}{*}{ Dummy 1975-1984 } & 1.338 & 1.332 & 1.342 & 1.349 \\
\hline & 0.515 & 0.438 & 0.414 & 0.414 \\
\hline \multirow[t]{2}{*}{ 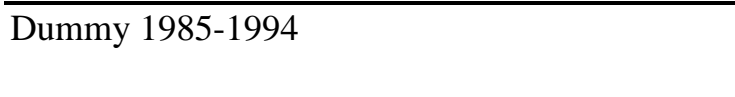 } & 2.259 & 2.209 & 2.218 & 2.23 \\
\hline & 0.691 & 0.58 & 0.548 & 0.549 \\
\hline \multirow[t]{2}{*}{ Dummy 1995-2003 } & 2.057 & 1.891 & 1.919 & 1.931 \\
\hline & 0.652 & 0.528 & 0.502 & 0.503 \\
\hline \multirow{2}{*}{$\begin{array}{l}\text { Labor Relations in 1999, instrumented with } \\
\text { strikes in 1960s }\end{array}$} & -0.927 & & -0.638 & -0.834 \\
\hline & 0.226 & & 0.238 & 0.207 \\
\hline \multirow[t]{2}{*}{ Replacement Rate } & & 0.01 & 0.015 & 0.018 \\
\hline & & 0.007 & 0.007 & 0.007 \\
\hline \multirow[t]{2}{*}{ Benefit Duration } & & 0 & -0.011 & \\
\hline & & 0.081 & 0.076 & \\
\hline \multirow[t]{2}{*}{ Union Coverage } & & 0.596 & 0.222 & \\
\hline & & 0.326 & 0.318 & \\
\hline \multirow[t]{2}{*}{ Employment Protection } & & 0.031 & 0.037 & 0.055 \\
\hline & & 0.03 & 0.028 & 0.023 \\
\hline \multirow[t]{2}{*}{ Active Labor Market Policies } & & 0.032 & 0.026 & 0.022 \\
\hline & & 0.012 & 0.011 & 0.009 \\
\hline \multirow[t]{2}{*}{ Union Density } & & 0.024 & 0.029 & 0.03 \\
\hline & & 0.008 & 0.008 & 0.007 \\
\hline \multirow[t]{2}{*}{ Tax Wedge } & & 0.039 & 0.018 & \\
\hline & & 0.013 & 0.013 & \\
\hline \multirow[t]{2}{*}{ Coordination of Bargaining } & & 0.766 & 0.55 & 0.45 \\
\hline & & 0.169 & 0.152 & 0.126 \\
\hline$\overline{\mathrm{N}}$ & 72 & 72 & 72 & 72 \\
\hline $\mathrm{R} 2$ & 0.645 & 0.749 & 0.781 & 0.773 \\
\hline
\end{tabular}

positive. Spain, Portugal and Greece are excluded from regression due to lack of meaningful strikes data in the 1960's. 


\section{Conclusions and open issues}

We see the point of our paper as arguing that, in addition to formal institutions, the quality of labor relations matters in the determination of unemployment. Faced with adverse shocks, such as those Europe has faced in the last three to four decades, countries with better relations appear to have been better able to limit the rise of unemployment and to turnaround faster thereafter.

This is both good and bad news for those who want to achieve lower unemployment in Europe. The good news is that, while institutional reform is clearly important, good labor relations, by themselves, go a long way. The bad news is that, based on the informal evidence as well as the correlation between our two measures of quality for the 1960s and the late 1990s, the quality of labor relations appears slow to change over time, if at all.

This last remark points to the obvious limit of our paper, namely the lack of a theory for what determines the quality of labor relations, and whether and how it can be improved over time. This is a large and difficult topic, and we shall limit ourselves to a few remarks ${ }^{3}$.

The quality of labor relations is clearly correlated with a number of union or country characteristics. The attitude of unions with respect to the profit rate of firms clearly differs between communist, socialist, and social-democratic unions. Most socialist and social-democratic unions now recognize the need for firms to maintain an adequate profit rate. The rhetoric of many communist unions, on the other hand, remains largely similar to what it was 30 years ago. The same holds not only for unions, but also for political par-

3. Müller and Philippon [2004] study the link between labor relations and the control of firms. They find that, across countries, bad labor relations are associated with more family control, while good labor relations are associated with more dispersed ownership of shares. They argue that bad labor relations and tight family control reinforce each other. This may explain the persistence of bad and good relations that we see in the data. 
ties. ${ }^{4}$ Our quality measure is indeed strongly correlated with the number of communist votes in elections in the 1960s. Whether this should be taken as correlation, or as a proximate cause for the quality of labor relations, is still unclear.

Some evidence suggests, however, that the quality of labor relations can change over time. The example of the UK appears relevant here. Unions were surely made weaker by the policies of Margaret Thatcher; but there is wide agreement that they have also changed their attitude (although the improvement in the quality of labor relations is not visible in our Figure 3, where the UK is right on the regression line...)

4. Indeed, the best known early statement of the need for "a partnership between capital and labor" is by Helmut Schmidt, then the Social Democratic Chancellor of Germany, in 1976: "The profits of entreprises today are the investments of tomorrow, and the investments of tomorrow are the jobs of the day after". 


\section{Appendix. Derivation of the wage under learning.}

Let $p_{t}$ be the subjective probability held by the union at time $t$ that $\tilde{g}=g$, and let $p_{0}$ be the prior. From the realized employment $n_{t}$, the union can extract $a_{t}$ but not $a_{t}^{*}$. The information set at the end of period $t$ is therefore $\Omega_{t}=\left\{a_{0}, a_{1}, . ., a_{t}\right\}$.

Under the assumption that the union sets the wage one period in advance, to maximize the expected wage bill

$$
\hat{w}_{t+1}=\arg \max _{w_{t+1}} E_{t}\left[w_{t+1} n_{t+1}\right]
$$

the wage is given by:

$$
\hat{w}_{t+1}=\frac{\phi}{E_{t}\left[a_{t+1}^{-1}\right]}=\frac{\phi e^{-\frac{\sigma^{2}}{2}}}{E_{t}\left[\left(a_{t+1}^{*}\right)^{-1}\right]}
$$

where $\phi \equiv \frac{1-r+\frac{1}{\theta}}{2}$.

Bayesian learning in turn implies

$$
\begin{aligned}
p_{t} & =\operatorname{prob}\left(\tilde{g}=g \mid \Omega_{t-1}, a_{t}\right) \\
& =\frac{\operatorname{prob}\left(a_{t} \mid \Omega_{t-1}, \tilde{g}=g\right) \operatorname{prob}\left(\tilde{g}=g \mid \Omega_{t-1}\right)}{\operatorname{prob}\left(a_{t} \mid \Omega_{t-1}\right)} \\
& =\frac{p_{t-1}}{p_{t-1}+\left(1-p_{t-1}\right) \exp \left(\frac{1}{2 \sigma^{2}}\left(\left(\log a_{t}-g t\right)^{2}-\left(\log a_{t}\right)^{2}\right)\right)}
\end{aligned}
$$

Along the path where $\varepsilon=0$ and $\tilde{g}=0$, we have

$$
p_{t}=\frac{p_{t-1}}{p_{t-1}+\left(1-p_{t-1}\right) \exp \left(\frac{(g t)^{2}}{2 \sigma^{2}}\right)}
$$


where we see that $p_{t}$ decreases toward 0 . Along this path, the wage is

$$
\hat{w}_{t}=\frac{\phi e^{-\frac{\sigma^{2}}{2}}}{p_{t-1} e^{-g t}+1-p_{t-1}}
$$

and employment is

$$
n_{t}=1+\theta\left(1-\hat{w}_{t}-r\right)
$$

The values used to derive the path in Figure 2 are $p(0)=0.98, g=.01$, $\sigma=.02, r=.1$ and $\theta=1$. 


\section{References}

[1] Olivier Blanchard and Justin Wolfers. Shocks and institutions and the rise of European unemployment. The aggregate evidence. Economic Journal, 110(1):1-33, March 2000.

[2] Douglas Hibbs. The political economy of industrial democracies. Harvard University Press, 1987.

[3] Peter Katzenstein. Small states in world markets. Cornell University Press, 1985.

[4] Holger Müller and Thomas Philippon. Corporate ownership and labor relations (around the world). mimeo NYU, 2004.

[5] Stephen Nickell and Jan van Ours. The Netherlands and the United Kingdom: a European unemployment miracle. Economic Policy, 30, April 2000.

[6] Ronald Schettkat. Are institutional rigidities at the root of European unemployment? Cambridge Journal of Economics, 27:771-787, 2003.

[7] Jelle Visser and Anton Hemerijck. A Dutch miracle. Job growth, welfare reform and corporatism in the Netherlands. Amsterdam University Press, Amsterdam, 1997. 